\title{
Pengaruh HSV Pada Pengolahan Citra Untuk Kematangan Buah Cabai
}

\author{
Arifiyanto Hadinegoro*, Dicky Andhika Rizaldhi \\ Fakultas Ilmu Komputer, Informatika, Universitas Amikom, Yogyakarta, Indonesia \\ Email: 1,"arifiyanto@amikom.ac.id, ${ }^{2}$ dicky.1428@students.amikom.ac.id \\ Email Penulis Korespondensi: arifiyanto@amikom.ac.id \\ Submitted: 13/12/2021; Accepted: 25/12/2021; Published: 31/12/2021
}

\begin{abstract}
Abstrak-Pengenalan citra atau gambar memiliki tahapan yang cukup komplek agar komputer mampu mengenali objek apa yang akan diidentifikasi, ada beberapa tahapan yang digunakan dalam melakukan proses pengolahan citra, input data ekstraksi citra dan klasifikasi citra, Pada penelitian ini akan menguji sejauh mana algoritma untuk ekstraksi memberikan pengaruh pada hasil akhir klasifikasi. Penelitian ini menggunakan citra cabai sebagai bahan pengujian dan hasil pengujian berupa pengenalan cabai dengan 4 tingkat, matang, setengah matang, mentah dan busuk. Penelitian ini juga menggunakan tools untuk melakukan proses pengenalan citra, Metode pengenalan citra yang digunakan dalam penelitian ini adalah Hue Saturation Value (HSV) Gray Level Co-occurrence Matrix (GLCM) dan Learning Vector Quantization (LVQ3) untuk klasifikasinya, dalam prosesnya akan diuji coba dengan 2 skenario pengenalan citra, metode pertama menggunakan GLCM dan LVQ3, skenario ke 2 menggunakan HSV GLCM dan LVQ3. Hasil dari penelitian ini adalah melihat seberapa besar pengaruh HSV pada proses pengenalan citra digital cabai, hasil ekstraksi menggunakan ekstraksi GLCM Klasifikasi LVQ 3 yakni 59,58\%, Dan hasil Klasifikasi LVQ3 menggunakan ekstraksi HSV dan GLCM menghasilkan 93,58\%. Kesimpulannya metode ekstraksi HSV memberikan tambahan 34\% akurasi dibandingkan dengan hanya menggunakan GLCM sebagai metode ekstraksi.
\end{abstract}

\section{Kata Kunci: GLCM; HSV; LVQ3; Cabai; Ekstraksi}

\begin{abstract}
Image or image recognition has quite complex stages so that the computer is able to recognize what objects to identify, there are several stages used in the image processing process, image extraction data input and image classification, this study will examine the extent to which the algorithm for extraction have an influence on the final classification results. This study us es the image of chili as a test material and the results of the test are the introduction of chili with 4 levels, ripe, half cooked, raw and rotten. This study also uses tools to perform the image recognition process. The image recognition method used in this study is Hue Saturation Value (HSV) Gray Level Co-occurrence Matrix (GLCM) and Learning Vector Quantization (LVQ3) for classification, in the process it will be tested. With 2 image recognition scenarios, the first method uses GLCM and LVQ3, the second scenario uses HSV GLCM and LVQ3. The results of this study are to see how much influence HSV has on the digital image recognition process of chili, the extraction results using GLCM extraction LVQ3 classification is 59.58\%, and the results of LVQ3 classification using HSV and GLCM extraction yields 93.58\%. In conclusion, the HSV extraction method provides an additional $34 \%$ accuracy compared to using only GLCM as the extraction method.
\end{abstract}

Keywords: GLCM; HSV; LVQ3; Chili; Extraction

\section{PENDAHULUAN}

Kemajuan teknologi di bidang citra digital saat ini mengalami kemajuan yang sangat pesat. Banyak bidang yang telah menerapkan kemajuan citra digital salah satunya bidang pertanian dan pangan [1] [2]. Dimana banyak penggunaan citra digital di bidang pertanian dan pangan telah menghasilkan respon yang memuaskan [3].

Pengolahan citra digital atau yang sering disebut digital image processing saat ini telah digunakan sangat luas. Pemanfaatan kelebihan dari image processing untuk mempermudah suatu pekerjaan sangat menguntungkan karena dapat memaksimalkan sebuah pekerjaan menjadi lebih cepat, tepat dan efektif . Pengolahan citra digital sendiri merupakan sebuah teknik manipulasi dan interpretasi dari sebuah citra secara komputasi dengan cara memodifikasi citra digital untuk menghasilkan sebuah informasi $[4,5,6]$.

Komputer memerlukan beberapa tahap dalam pengolahan citra digital diantaranya adalah ekstraksi dan klasifikasi, metode ekstraksi yang akan digunakan dalam penelitian ini adalah Gray Level Co-occurrence Matrix (GLCM) serta Hue Saturation Value (HSV) dan metode klasifikasi yang akan digunakan adalah Learning Vector Quantization (LVQ 3). GLCM merupakan metode yang digunakan untuk memberikan informasi pada citra dengan memanfaatkan tekstur warna dari citra itu sendiri menggunakan dua nilai pixel pada jarak dan arah tertentu dengan menghitung dari probabilitas nilai tingkat keabuan. Metode ini sering digunakan pada penelitian untuk identifikasi citra digital diantaranya yang dilakukan Mengira [4], Pamungkas [5] dan Mantika [6]. Untuk HSV adalah metode ekstraksi yang menggunakan Hue sesuai namanya yang di dapat dari konversi warna RGB. HSV merupakan warna yang memiliki segmentasi yang hampir mendekati warna yang bisa ditangkap oleh retina mata [9] [7] [8] [9], serta LVQ yang merupakan algoritma terwaris atau supervised learning dan memiliki jaringan berlayer tunggal ( single layer), [10]. LVQ 3 merupakan penyempurnaan dari LVQ sebelumnya dimana dilakukan penyempurnaan dalam pemilihan vektor untuk memastikan vektor pewakil agar selalu mendekati distribusi dari kelas yang di buat.

Hasil akhir dari pengenalan citra di dapat dari persentase hasil akhir metode klasifikasi yang dihitung dari bobot hasil ekstraksi citranya, hasil pengolahan citra sangat dipengaruhi oleh hasil ekstraksi, seperti pada penelitian yang dilakukan oleh Sudibyo dkk, menerapkan dua ekstraksi HSV dan GLCM dengan metode klasifikasi LVQ dalam membedakan daging babi dan daging sapi, hanya menghasilkan akurasi tertinggi $76.25 \%$ pada learning rater $=0.01$ dengan eph 0.1 dam epoch $=100$ [11]. Pada penelitian lain dilakukan oleh Sarimin dkk, menggunakan klasifikasi JST, 
dengan ekstraksi HSV dan GLCM, untuk mendeteksi kesegaran ikan bawal, memiliki tingkat akurasi yang rendah sekitar $50 \%$ untuk mendeteksi [12].

Dari kedua penelitian tersebut memiliki perbedaan pada metode klasifikasinya, dimana menggunakan klasifikasi Jaringan syaraf Tiruan mendapatkan hasil yang lebih rendah walau menggunakan dua metode ekstraksi, namun pada penelitian yang dilakukan Putra dan syarifa, mendapatkan akurasi tertinggi 100\% dalam identifikasi citra darah Leukemia, dengan menggunakan HSV, GLCM dan LVQ 3 sebagai klasifikasinya [13]. Ada juga penelitian dari Abilisa dkk untuk mendeteksi jenis kulit manusia dengan GLCM dan LVQ , mendapatkan nilai akurasi hanya $80 \%$ [14], Penelitian ini berfokus pada perbedaan penggunaan metode ekstraksi pada aplikasi pengenalan citra cabai, yaitu ekstraksi HSV dan GLCM, lalu ekstraksi GLCM saja, dari sisi teknis menggunakan satu metode ekstraksi aplikasi sudah mampu mengenali objek pada citra digital walau memiliki tingkat akurasi yang rendah, metode HSV pernah di uji performanya pada kasus deteksi kelayuan pada bunga mawar antara HSV dengan HSI ( Hue Saturation Intensity ) di penelitian ini menghasilkan HSI yang paling cepat proses nya [15]. Namun menggunakan 2 metode ekstraksi tidak menjamin memiliki akurasi yang tinggi dalam klasifikasinya jika dilihat pada penelitian sebelumnya. Maka penelitian ini mencoba melihat perbedaan penggunaan dua ekstraksi dan satu ekstraksi yaitu HSV dan GLCM pada pengolahan citra digital cabai,

Dalam paper ini digunakan cabai rawit sebagai objek penelitian seperti kita ketahui Cabai rawit atau yang memiliki nama latin Capsicum annuum 'Bird's Eye' merupakan bahan masakan yang memiliki cita rasa pedas yang sering digunakan masyarakat Indonesia. Selain sebagai bahan makanan, cabai rawit juga memiliki manfaat yang banyak salah satunya di bidang obat-obatan yakni sebagai bahan pembuatan koyo dan analgesic [16].

Pembuatan sistem nanti nya akan di buat di pengolahan citra matlab untuk mengenali citra cabai yang akan diklasifikasikan menjadi 4 kategori , matang, setengah matang, mentah dan busuk. Dan penelitian akan dicoba dengan dua scenario untuk melihat perbedaan menggunakan GLCM dan LVQ3, dengan GLCM ,HSV dan LVQ3 dalam hal persentase keakuratan nya.

\section{METODOLOGI PENELITIAN}

\section{1 Tahapan Penelitian}

Pada bagian ini menjelaskan tentang urutan dari tahapan penelitian, seperti terlihat pada gambar 1 dibawah. Metode dilakukan dimulai dari Pengumpulan data, pengolahan data, perancangan sistem, kemudian implementasi, dari implementasi ada pengujian pada sistem yang mana jika terjadi error pada sistem maka proses akan berulang pada perancangan kembali, namun jika sudah sesuai maka akan dilanjutkan dengan proses analisis data yang dihasilkan, terakhir melakukan dokumentasi kegiatan penelitian ini, gambar 1 menjelaskan alur dari mulai proses pengumpulan data hingga dokumentasi.

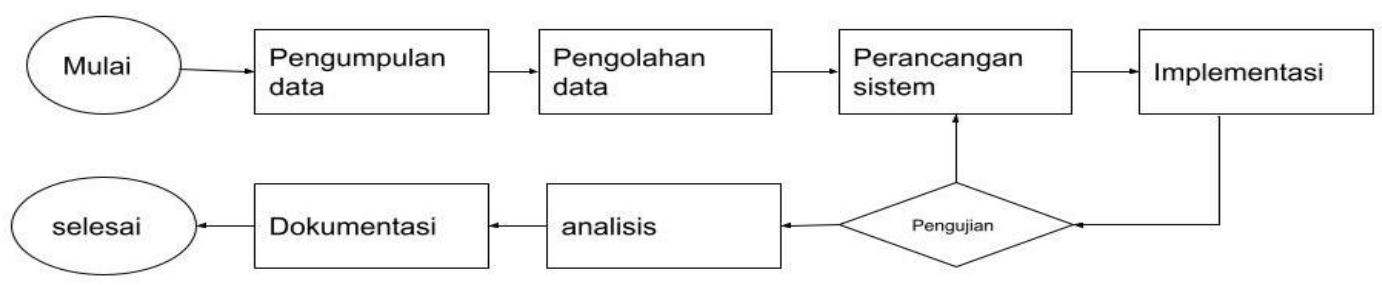

Gambar 1. Tahapan penelitian

Penelitian ini terdiri dari beberapa tahapan yang terlihat pada gambar 1 di bawah Setiap tahap yang ada pada alur penelitian merupakan proses tersendiri dan memiliki tujuan masing masing.

\subsubsection{Pengumpulan Data}

Pengumpulan data dilakukan dengan cara observasi langsung dengan mendatangi lapangan untuk mendapatkan data cabai, dan secara teori dilakukan dengan cara membaca buku literatur dan makalah yang berkaitan dengan pengolahan citra serta cabai. Dalam penelitian ini data yang dibutuhkan berupa data citra yang sebagai subjek penelitian, sampel data citra yang digunakan dalam bentuk *jpg, proses pengambilan data dilakukan secara langsung dengan kondisi yang telah disesuaikan yaitu dengan menggunakan background putih dengan Data yang diambil berjumlah 360 citra digital.

\subsubsection{Pengolahan Data}

Data yang di kumpulkan kemudia di olah dengan cara penyesuaian terhadap data digital yang akan di lakukan ektraksi, proses ini melakukan cropping terhadap citra untuk meminimalkan background yang ada sehingga object cabai lebih terlihat jelas, Ukuran citra yang dilakukan pengolahan ubah ukurannya menjadi 100 x 400 pixel yang bertujuan untuk mempercepat proses sistem. 
Building of Informatics, Technology and Science (BITS)

Volume 3, No 3, December 2021, Page 155-163

ISSN 2684-8910 (media cetak)

ISSN 2685-3310 (media online)

DOI 10.47065/bits.v3i3.1020

\subsubsection{Perancangan Sistem}

Proses ini dimulai dengan menentukan skenario pengujian yang akan dilakukan, yang pertama adalah pengujian dengan menggunakan 1 ekstraksi GLCM dan klasifikasi LVQ3 Alur sistem skenario 1 terlihat pada Gambar 2, yang kedua menggunakan 2 ekstraksi HSV, GLCM dan ekstraksi LVQ3, alur sistem scenario kedua dapat dilihat pada Gambar 3 di bawah ini.

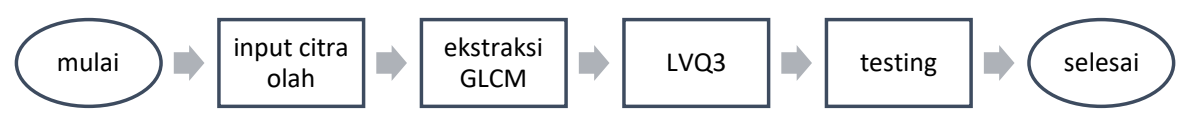

Gambar 2. Alur sistem skenario 1

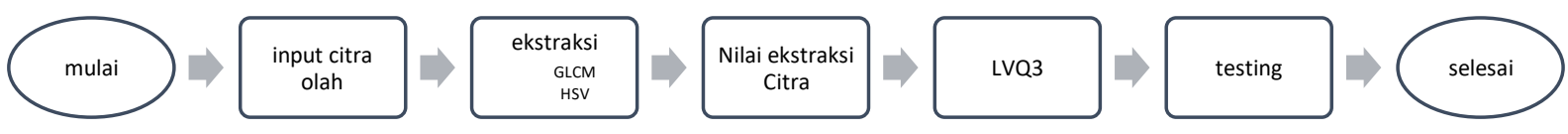

Gambar 3. Alur sistem skenario 2

Hasil dari HSV dan GLCM akan menjadi bobot yang nantinya melakukan klasifikasi dengan algoritma LVQ3 . Pada tahap ini, juga melakukan perancangan terhadap interface struktur menu dan perancangan interface dengan menggunakan tools pengolahan gambar di MATLAB. Perancangan interface di peruntukan agar memudahkan proses dari ekstraksi dan klasifikasi pada system, rancangan interface terlihat pada Gambar 4 di bawah

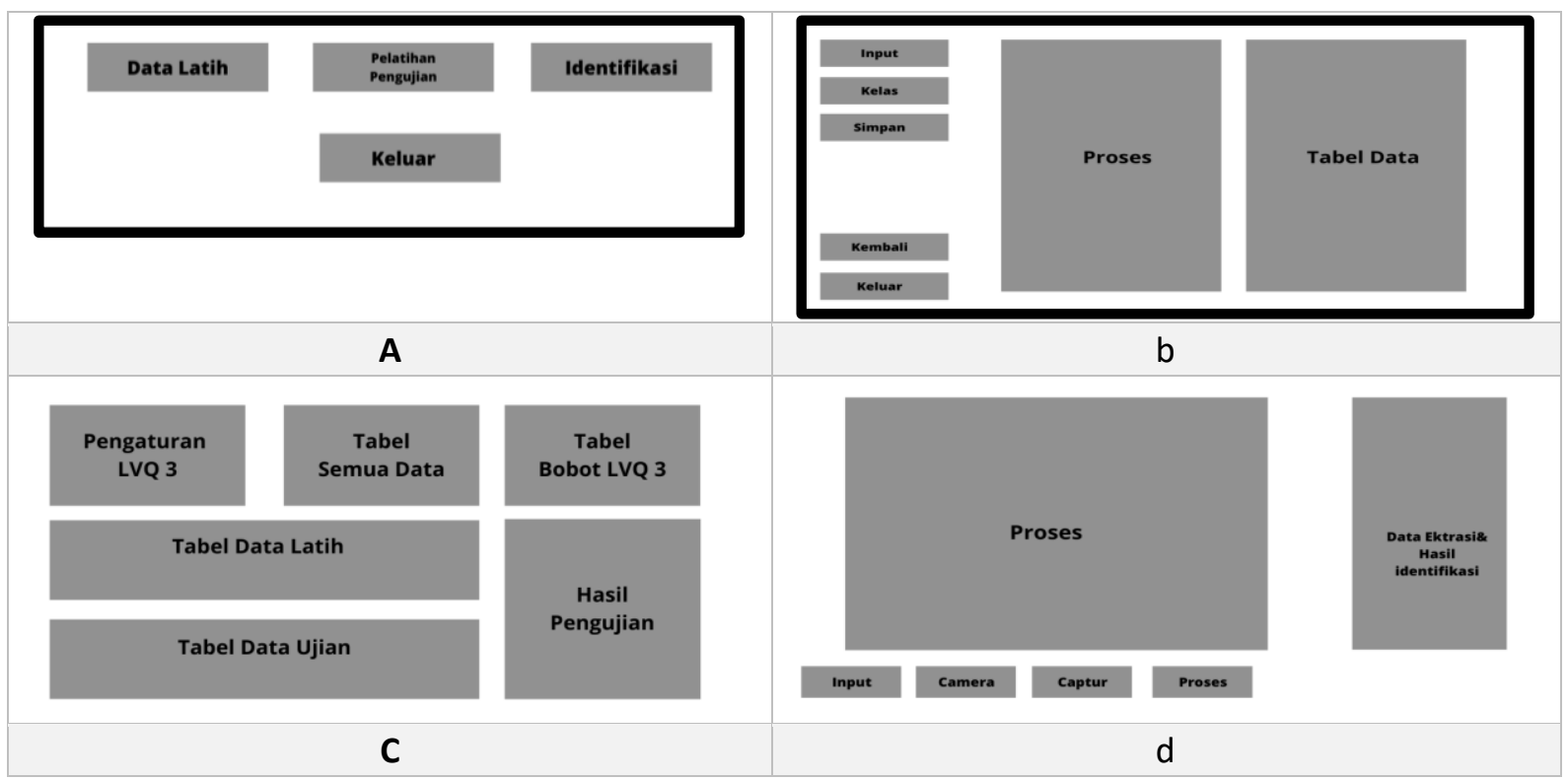

Gambar 4. Rancangan Layout aplikasi (a) menu utama (b) menu data latih (c) tampilan pelatihan pengujian (d) tampilan menu identifikasi.

Pada Gambar 4a merupakan rancangan tampilan halaman utama, gambar 4b merupakan rancangan tampilan data latih, gambar $4 \mathrm{c}$ rancangan tampilan dari tombol pelatihan dan pengujian, Gambar 4d adalah rancangan tampilan menu identifikasi.

\subsubsection{Implementasi}

Tahap ini merupakan proses dijalankannya data yang telah melewati proses pengolahan data dan skenario sistem yang dirancang pada aplikasi, Tahapan ini merupakan tahapan yang sangat penting dalam pembuatan sebuah sistem/aplikasi dimana sistem/aplikasi yang telah dirancang dan diimplementasikan akan diuji apakah telah sesuai dengan tujuan akhir dari penelitian ini. Pada tahap ini juga implementasi tampilan muka dari system diterapkan.

\subsubsection{Pengujian}

Tahapan ini juga akan dilakukan perbandingan dua metode klasifikasi yang berbeda dimana satu metode menggunakan ekstraksi HSV, GLCM dan klasifikasi LVQ 3 sedangkan metode yang lain hanya menggunakan ekstraksi GLCM dan Klasifikasi LVQ 3. Dengan data berjumlah 360 data dengan pembagian perbandingan data latih: data uji sebagai berikut 90:10, 80:20,70:30. Lalu Learning rate yang digunakan 0.1, 0.3, 0.5, 0.7, dengan Epoh yang digunakan 100. Dalam tahap ini juga temasuk pengujian terhadap fungsi fungsi tombol pada tampilan system yang di buat. 


\subsubsection{Analisis}

Pada tahap pengujian akan menghasilkan sebuah kesimpulan dari parameter yang ada. Kesimpulan itu akan menghasilkan sebuah analisis terhadap sistem yang telah dibuat. Dimana analisis ini akan memaparkan hasil yang diperoleh dari dua metode yang berbeda saat dilakukan pengujian berupa perbandingan akurasi. Akurasi yang dimaksud adalah perbandingan data antara metode menggunakan ekstraksi GLCM, HSV dan klasifikasi LVQ3, serta ekstraksi GLCM dan klasifikasi LVQ3.

\subsubsection{Dokumentasi}

Pada tahapan ini dilakukan penyusunan dokumentasi dari hasil penelitian yang disusun menjadi sebuah karya penelitian berupa makalah publikasi atau jurnal. Selain itu juga dilakukan dokumentasi terhadap sistem yang telah dibuat agar memudahkan para penelitian yang untuk mengembangkan

\section{HASIL DAN PEMBAHASAN}

\section{1 Hasil pengumpulan data.}

Data yang dibutuhkan berupa data citra yang sebagai subjek penelitian, sampel data citra yang digunakan dalam bentuk *jpg, proses pengambilan data dilakukan secara langsung dengan kondisi yang telah disesuaikan yaitu dengan menggunakan background putih dengan Data yang diambil berjumlah 360 citra, contoh hasil pengambilan citra ada pada Gambar 5 dibawah.

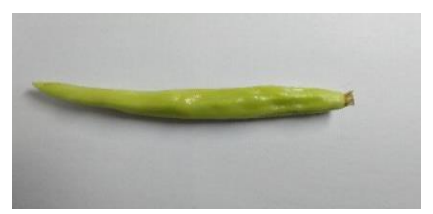

Gambar 5. Contoh citra cabai

Citra diatas merupakan salah satu hasil dari pengambilan secara langsung oleh penulis, data ini selanjutnya akan melalui proses selanjutnya agar mudah untuk dilakukan ekstraksi.

\section{2 Hasil Pengolahan Data}

Dari data yang diperoleh maka selanjutnya dilakukan proses pengolahan data, proses ini melakukan cropping terhadap citra untuk meminimalkan background yang ada sehingga object cabai lebih terlihat jelas, kemudian citra digital diubah ukurannya menjadi 100 x 400 pixel. Pada Gambar 6 merupakan citra asli dan citra yang telah dilakukan cropping.

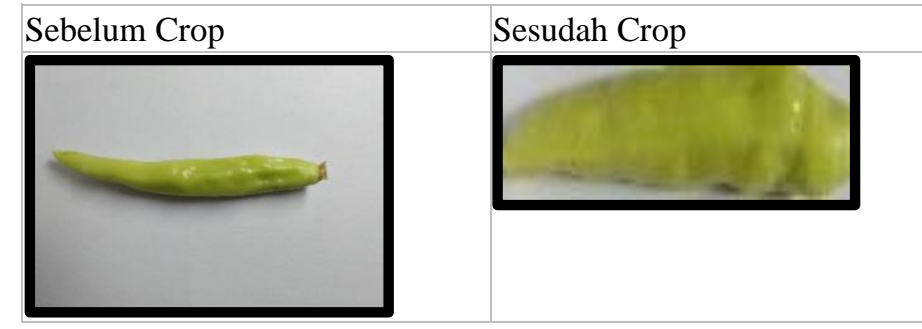

Gambar 6. Citra sebelum dan sesudah Crop

Gambar sebelah kanan merupakan hasil dari crop.

\section{3 Perancangan sistem}

Pada tahap ini perancangan dari 2 skenario pada metodologi penelitian diterapkan di mana setiap proses pada scenario di implementasikan pada system, sesuai pada alur scenario 1 pada gambar 2. Data hasil preprocessing atau dari pengolahan data di atas diinputkan sebagai subjek proses pengenalan object nya. Data data yang digunakan adalah data hasil proses pengolahan.

\subsection{Ekstraksi GLCM}

Dimana pada GLCM akan diolah untuk mendapatkan nilai dari fitur pada GLCM yakni Angular Second Moment, Contrast, Correlation, Variance, Inverse Difference Moment, dan Entropy dimana nantinya data nilai tersebut kemudian diolah lagi untuk dijadikan bobot dalam klasifikasi secara alur bisa di lihat pada Gambar 6 flowchart GLCM. 
Building of Informatics, Technology and Science (BITS)

Volume 3, No 3, December 2021, Page 155-163

ISSN 2684-8910 (media cetak)

ISSN 2685-3310 (media online)

DOI 10.47065/bits.v3i3.1020

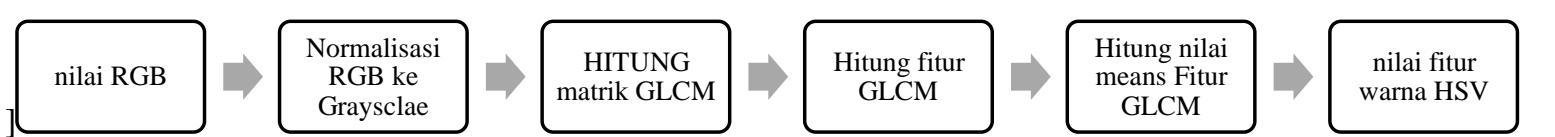

Gambar 7. Flowchart GLCM

Untuk Formula yang diterapkan Angular Second Moment digunakan untuk mengukur konsentrasi intensitas keabuan (1).lalu Contrast menunjukkan perbedaan intensitas keabuan dalam citra (2), kemudian mencari nilai Correlation digunakan dalam menunjukkan ketergantungan linear antara nilai derajat keabuan dalam citra (3), Variance menunjukkan variasi dari elemen matriks kookurensi(4), Inverse Different Moment atau IDM menunjukkan nilai kehomogenan (5), Entropi pada GLCM menunjukkan ukuran ketidakaturan dari distribusi intensitas keabuan suatu citra pada matriks kookurensi (6).

$$
\begin{gathered}
A S M=\sum_{i=1}^{L} \mathbf{\square} \sum_{j=1}^{L} \mathbf{\square}\{P(i, j)\}^{2} \\
\text { Con }=\sum_{n=1}^{L} \mathbf{\square} \sum_{|i-j|=n}^{\mathbf{\square}}(i-j)^{2} P(i, j) \mathbf{\square} \\
\text { Cor }=\frac{\sum_{i=1}^{L} \mathbf{\square} \sum_{j=1}^{L} \mathbf{\square}\{(i, j)\}\{P(i, j)\}-\mu_{i} \mu_{j}}{\sigma_{i} \sigma_{j}} \\
V A R=\sum_{i}^{L} \mathbf{\square} \sum_{j}^{L} \mathbf{\square}\left\{\left(i-\mu_{x}\right)\right\}\left\{\left(j-\mu_{y}\right)\right\} p(i, j) \\
\text { IDM }=\sum_{i=1}^{L} \mathbf{\square} \sum_{j=1}^{L} \mathbf{\square} \frac{\{P(i, j)\}}{1+(i-j)^{2}} \\
\text { Entropy }=\sum_{i=1}^{L} \mathbf{\square} \sum_{j=1}^{L} \mathbf{\square}\{P(i, j)\} \log \{P(i, j)\}
\end{gathered}
$$

\subsection{Ekstraksi HSV}

Pada penelitian ini dilakukan 2 ekstraksi yakni warna dan tekstur. Diman dalam ekstraksi warna penelitian ini menggunakan metode ekstraksi HSV. Pola ekstraksi HSV bisa di lihat pada Gambar 8 flowchart Alur HSV

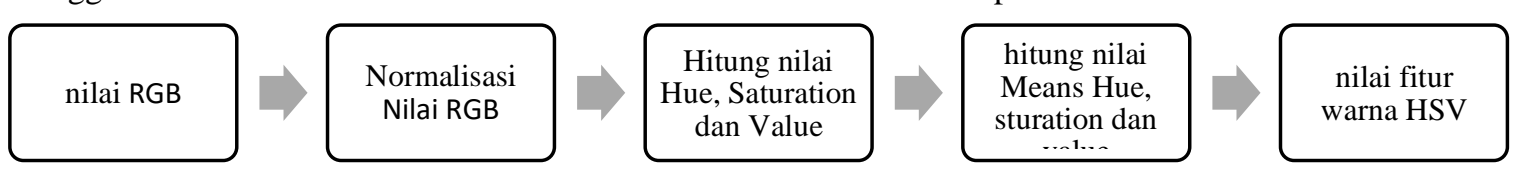

\section{Gambar 8. Flowchart Alur HSV}

Dalam menentukan nilai HSV diperlukan nilai RGB yang dapat dicari menggunakan rumus (7)(8)(9). Hasil dari RGB akan dikonversi ke HSV dengan menggunakan rumus (10)(11)(12) Value atau disebut juga intensity yaitu ukuran seberapa besar kecerahan dari suatu warna atau seberapa besar cahaya datang dari suatu warna. Value dapat bernilai dari 0-100\% berikut [17]:

Menghitung nilai value

$$
\begin{aligned}
& r=R /(R+G+B) \\
& g=G /(R+G+B) \\
& b=B /(R+G+B)
\end{aligned}
$$

$$
V=\max (r, g, b)
$$

Menghitung Nilai saturasi :

$$
\begin{aligned}
& S=\left\{0 j i k a V=0 \frac{(r, g, b)}{V} \text { jika } V>0\right. \\
& H=\frac{60 x(g-b)}{S x V} \text { jika } V=r \\
& H=60 x\left[2+\frac{(b-r)}{S x V}\right] j i k a V=g \\
& H=60 X\left[4+\frac{(r-g)}{S x V}\right] \text { jika } V=B
\end{aligned}
$$




\subsection{Klasifikasi LVQ3}

LVQ 3 merupakan penyempurnaan dari LVQ 2.1 yang mana dalam LVQ 2.1 terdapat kelemahan yakini mengalami divergensi selama proses pelatihan dan dilakukan penyempurnaan pada LVQ 3. LVQ3 dilakukan penyempurnaan dalam pemilihan vektor dimana. Vektor diambil dari kelas terdekat agar selalu mendekati distribusi dari kelas tersebut[14]. Untuk proses update antara LVQ 2.1 dan LVQ 3 sama hanay terdapat perbedaan dalam aturan tmbahan pada LVQ 3 dimana jika dalam LVQ 3 jika terdapat dua buah vector yang asalnya dari kelas yang sama maka proses update dari vektor menggunakan aturan berikut :

$$
w 1=w 1+\varepsilon * \alpha *(w-x i), \varepsilon>0
$$

\section{4 Implementasi}

Hasil rancangan tampilan sistem di sesederhana mungkin agar mudah dipahami dan tidak terlalu membenci komputasi komputer, hasil dari tampilan terlihat pada Gambar 9 di bawah.

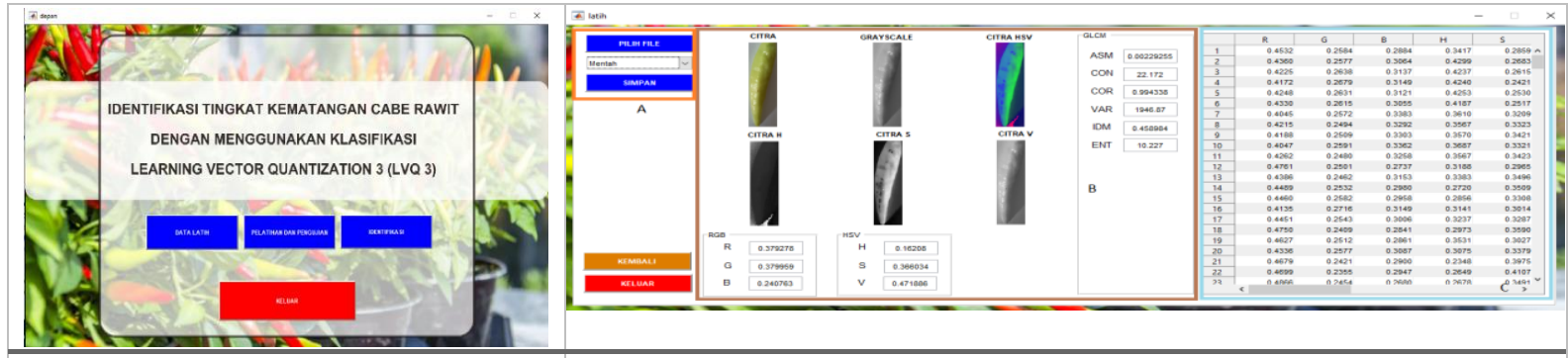

(a) Tampilan menu utama

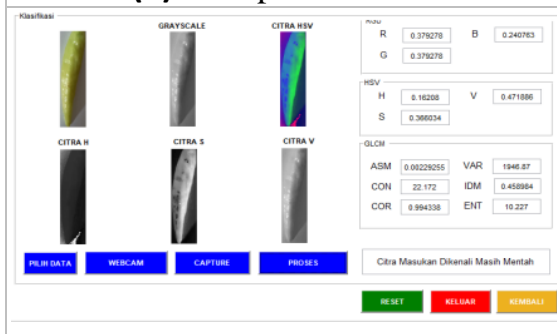

(d) Tampilan menu identifikasi. (b)tampilan menu data latih

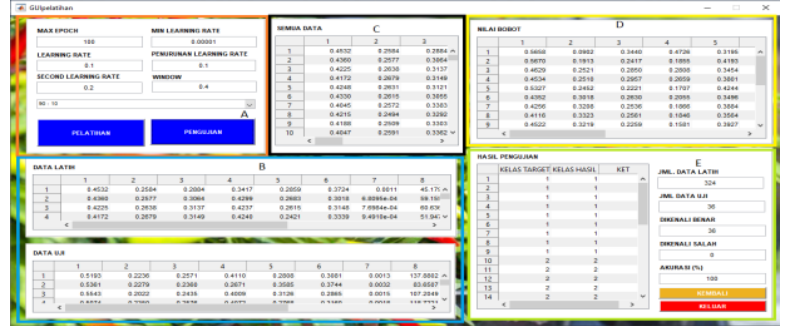

(c) Tampilan pengujian dan pelatihan

Gambar 9. Hasil tampilan menu system (a) menu utama (b) menu data latih (c) tampilan pelatihan pengujian (d) tampilan menu identifikasi.

Gambar 9a adalah tampilan dari halaman utama sistem, gambar 9b tampilan hasil menu data latih, pada tampilan ini di perlihatkan proses hasil dari ekstraksi pada citra, mulai dari awal citra hingga pada tampilan hasil HSV, pada kolom sebelahnya menampilkan tabel nilai dari citra di samping nya Gambar 9 (c) tampilan pengujian dan pelatihan, menunjukkan proses dari setiap algoritma yang digunakan (d) tampilan menu identifikasi, adalah tampilan dari sistem untuk melakukan identifikasi pada citra yang akan diklasifikasikan.

\subsection{Pengujian}

Proses Pengujian pada paper ini dilakukan dengan melakukan uji dari dari fungsi utama sisitem yang dibuat yaitu fungsi ektraksi GLCM dan HSV dalam klasifikasi LVQ 3. Data uji yang digunakan dalam pengujian menggunakan nilai mean dari setiap bobot ekstraksi. Selaiin itu dilakukan dua pengujian untuk meberikan kesimpulan apakah sistem yang digunakan sudah sesuai dengan tujuan awal penelitian.

Adapun pengujian sebagai berikut: Pengujian dilakukan dengan mempertimbangkan ciri dari citra baik warna, tekstur warna dengan menggunakan nilai epoh 100 dan learning rate yang digunakan $0.1,0.3,0.5,0.7$. Dengan banyak data set sebanyak 360 dengan perbandingan data latih dan data uji sebagai berikut 90:10, 80:20, 70:30. Dimana system/aplikasi akan dibandingkan yakni LVQ 3 dan GLCM tanpa HSV antara sistem LVQ 3 dan GLCM yang menggunakan HSV. Adapun hasil yang diperoleh ditunjukan pada Tabel 2 dan Gambar 4.

\subsubsection{Pengujian Data Testing}

Pada penelitian ini dilakukan testing dengan menggunakan sampel data berjumlah 16 data dari 360 data citra dengan perbandingan data latih dan data uji yakni $90: 10,80: 20,70: 30$, dimana dari 16 sempel terdapat 4 buah cabai data yang matang, 4 buah cabai data yang setengah matang, 4 buah cabai data yang mentah, dan 4 buah cabai data yang busuk. Yang sudah di-resize ukuran $100 * 400$ pixel dan diberi label masing. Adapun proses identifikasi ditunjukan pada Gambar 9d di atas . Pada Table 1 menjelaskan hasil dari data uji menggunakan data testing 
Tabel 1. Hasil Data Uji

\begin{tabular}{lllll}
\hline No & Gambar & Label & Hasil Identifiksi & Setatus \\
\hline 1 & Matang & Matang & Benar \\
2 & Matang & Matang & Benar \\
3 & Matang & Matang & Benar \\
4 & Matang & Matang & Benar \\
5 & Setengah Matang & Setengah Matang & Benar \\
6 & Setengah Matang & Setengah Matang & Benar \\
7 & Setengah Matang & Setengah Matang & Benar \\
8 & Mentah & Setengah Matang & Benar \\
9 & Mentah & Mentah & Benar \\
10 & Mentah & Mentah & Benar \\
11 & Mentah & Mentah & Benar \\
12 & Busuk & Busuk & Benar \\
13 & Busuk & Busuk & Benar \\
14 & Busuk & Busuk & Benar \\
15 & Busuk & Busuk & Benar \\
16 & & &
\end{tabular}
$100 \%$

Dari data testing yang diidentifikasi dengan jumlah 16 data dan telah diberi tabel hasilnya menunjukkan akurasi

\subsubsection{Pengujian Scenario 1}

Tahap ini adalah tahap scenario satu dijalankan yaitu menggunakan ekstraksi GLCM dan klasifikasi LVQ3, dengan kondisi yang sama seperti yang di tulis pada Gambar 2 Alur sistem skenario 1 diatas, hasil yang di dapat tersaji pada Tabel 3 Hasil skenario 1 di bawah.

Tabel 2. Hasil skenario 1

\begin{tabular}{|c|c|c|c|}
\hline Nilai Learning Rate & Epoh & Latih : Pengujian & $\begin{array}{l}\text { Nilai Akurasi } \\
\text { Ekstraksi GLCM dan Klasifikasi LVQ } 3\end{array}$ \\
\hline \multirow{3}{*}{0.1} & & $90: 10$ & $75 \%$ \\
\hline & & $80: 20$ & $64 \%$ \\
\hline & & $70: 30$ & $61 \%$ \\
\hline \multirow{3}{*}{0.3} & & $90: 10$ & $61 \%$ \\
\hline & & $80: 20$ & $58 \%$ \\
\hline & 100 & $70: 30$ & $53 \%$ \\
\hline \multirow{3}{*}{0.5} & 100 & $90: 10$ & $53 \%$ \\
\hline & & $80: 20$ & $58 \%$ \\
\hline & & $70: 30$ & $52 \%$ \\
\hline \multirow{3}{*}{0.7} & & $90: 10$ & $64 \%$ \\
\hline & & $80: 20$ & $60 \%$ \\
\hline & & $70: 30$ & $56 \%$ \\
\hline Rata Pengujian & & & $59,58 \%$ \\
\hline
\end{tabular}

Dari tabel 2 di atas menunjukkan ekstraksi tanpa menggunakan HSV hanya mencapai maksimal $61 \%$ dan minimal 56\% dengan rerata pengujian adalah 59.58\%

\subsubsection{Pengujian Scenario 2}

Tahap ini adalah tahap scenario satu dijalankan yaitu menggunakan ekstraksi GLCM dan HSV menggunakan klasifikasi LVQ3, dengan kondisi yang sama seperti yang di tulis pada gambar 3 alur sistem skenario 2 diatas menghasilkan nilai akurasi yang tersaji pada tabel 3 di bawah ini,

Tabel 3. Hasil skenario 2

\begin{tabular}{lcll}
\hline Nilai Learning Rate & Epoh & Latih : Pengujian & $\begin{array}{l}\text { Nilai Akurasi } \\
\text { Ekstraksi GLCM, HSV dan Klasifikasi LVQ 3 }\end{array}$ \\
\hline \multirow{2}{*}{0.1} & \multirow{2}{*}{100} & $90: 10$ & $100 \%$ \\
\cline { 2 - 3 } & $80: 20$ & $99 \%$ \\
\hline
\end{tabular}


Building of Informatics, Technology and Science (BITS)

Volume 3, No 3, December 2021, Page 155-163

ISSN 2684-8910 (media cetak)

ISSN 2685-3310 (media online)

DOI 10.47065/bits.v3i3.1020

\begin{tabular}{|c|c|c|c|}
\hline \multirow[t]{2}{*}{ Nilai Learning Rate } & Epoh & Latih : Pengujian & $\begin{array}{l}\text { Nilai Akurasi } \\
\text { Ekstraksi GLCM, HSV dan Klasifikasi LVQ } 3\end{array}$ \\
\hline & & $70: 30$ & $81 \%$ \\
\hline \multirow{3}{*}{0.3} & & $90: 10$ & $94 \%$ \\
\hline & & $80: 20$ & $97 \%$ \\
\hline & & $70: 30$ & $93 \%$ \\
\hline \multirow{3}{*}{0.5} & & $90: 10$ & $97 \%$ \\
\hline & & $80: 20$ & $97 \%$ \\
\hline & & $70: 30$ & $90 \%$ \\
\hline \multirow{3}{*}{0.7} & & $90: 10$ & $89 \%$ \\
\hline & & $80: 20$ & $93 \%$ \\
\hline & & $70: 30$ & $93 \%$ \\
\hline Rata Pengujian & & & $93,58 \%$ \\
\hline
\end{tabular}

Dari tabel 2 di atas menunjukkan ekstraksi menggunakan HSV dan GLCM mencapai maksimal $100 \%$ dan minimal $93 \%$ dengan rerata pengujian adalah $93.58 \%$

\subsection{Analisa}

Hasil dari pengujian menunjukan bahwa dengan menggunakan ekstraksi HSV dan GLCM memiliki akurasi yang lebih tinggi dari pada aplikasi yang hanya menggunakan GLCM dalam mengklasifikasi dengan menggunakan LVQ 3. Dengan perbandingan akurasi Ekstraksi HSV dan GLCM Klasifikasi LVQ3 dengan GLCM Klasifikasi LVQ3 yakni $93.58 \%$; 59.58\% dengan perbandingan bobot $1.57: 1$.

Detail dari hasil kedua skenario bisa di lihat pada Tabel 4 bawah, nilai pada setiap nilai rate memiliki perbedaan pada tiap prosesnya, perubahan nilai akurasi berdasarkan nilai rate tersaji pada Tabel 4 Tabel perbandingan hasil skenario di bawah ini

Tabel 4. Tabel perbandingan hasil skenario

\begin{tabular}{|c|c|c|c|c|}
\hline \multirow{2}{*}{$\begin{array}{c}\text { Nilai } \\
\text { Learning } \\
\text { Rate }\end{array}$} & \multirow[t]{2}{*}{ Epoh } & \multirow[t]{2}{*}{ Latih : Pengujian } & \multicolumn{2}{|c|}{ Nilai Akurasi } \\
\hline & & & $\begin{array}{l}\text { Ekstraksi GLCM, HSV dan } \\
\text { Klasifikasi LVQ } 3\end{array}$ & $\begin{array}{l}\text { Ekstraksi GLCM dan } \\
\text { Klasifikasi LVQ } 3\end{array}$ \\
\hline \multirow{3}{*}{0.1} & \multirow{12}{*}{100} & $90: 10$ & $100 \%$ & $75 \%$ \\
\hline & & $80: 20$ & $99 \%$ & $64 \%$ \\
\hline & & $70: 30$ & $81 \%$ & $61 \%$ \\
\hline \multirow{3}{*}{0.3} & & $90: 10$ & $94 \%$ & $61 \%$ \\
\hline & & $80: 20$ & $97 \%$ & $58 \%$ \\
\hline & & $70: 30$ & $93 \%$ & $53 \%$ \\
\hline \multirow{3}{*}{0.5} & & $90: 10$ & $97 \%$ & $53 \%$ \\
\hline & & $80: 20$ & $97 \%$ & $58 \%$ \\
\hline & & $70: 30$ & $90 \%$ & $52 \%$ \\
\hline \multirow{3}{*}{0.7} & & $90: 10$ & $89 \%$ & $64 \%$ \\
\hline & & $80: 20$ & $93 \%$ & $60 \%$ \\
\hline & & $70: 30$ & $93 \%$ & $56 \%$ \\
\hline \multicolumn{3}{|c|}{ Rata Pengujian } & $93,58 \%$ & $59,58 \%$ \\
\hline
\end{tabular}

\section{KESIMPULAN}

Berdasarkan hasil pembahasaan yang telah dibahas pada bab sebelumnya maka dapat dibuat kesimpulan sebagai berikut : Secara teknis identifikasi citra digital cabagi masih bisa dikenali walau dengan nilai akurasi $75 \%$ yang tertinggi dan yang terendah adalah 59\%, hasil ini didapat dengan menggunakan ekstraksi GLCM saja, sedangkan jika menggunakan HSV dan GLCM nilai akurasi naik menjadi $100 \%$ yang tertinggi dan $95 \%$ yang terendah. Klasifikasi buah cabai dari tingkat kematangan menggunakan LVQ 3 dengan ekstraksi HSV dan GLCM memiliki kinerja yang cukup baik dengan beberapa percobaan dengan nilai Learning Rate yang berbeda-beda yakni 0.1, 0.3, 0.5, dan 0.7 memiliki nilai rata-rata akurasi 93,58\%. Sehingga metode Klasifikasi LVQ3 dengan ekstraksi HSV dan GLCM dapat diimplementasikan untuk mengklasifikasi buah cabai. Pada perbandingan Learning Rate dapat disimpulkan bahwa semakin tinggi Learning Rate maka semakin rendah akurasinya ini disebabkan semakin tinggi Learning Rate maka program akan menjadi tidak stabil dan semakin kecil Learning Rate menyebabkan proses pembelajaran semakin lama. Dalam klasifikasi menggunakan LVQ 3 dengan menggunakan HSV dan GLCM memiliki nilai yang lebih tinggi dari 
Building of Informatics, Technology and Science (BITS)

Volume 3, No 3, December 2021, Page 155-163

ISSN 2684-8910 (media cetak)

ISSN 2685-3310 (media online)

DOI 10.47065/bits.v3i3.1020

pada yang hanya menggunakan GLCM saja. Dengan perbandingan akurasi Ekstraksi HSV dan GLCM Klasifikasi LVQ 3 dengan GLCM Klasifikasi LVQ3 yakni 93,58\% ; 59,58\% dengan perbandingan bobot 1.57 : 1. Dimana Penambahan ekstraksi warna menggunakan HSV mempengaruhi tingkat akurasi sekitar 34\%.

\section{REFERENCES}

[1] y. p. wiharja dan A. Harjoko, "Pemrosesan Citra Digital untuk Klasifikasi Mutu Buah Pisang Menggunakan Jaringan Saraf Tiruan,” IJEIS, pp. 57-58, 2014.

[2] A. Jakarta, S. Mu'minah, D. Riana dan S. Hadianti, "Klasifikasi Varietas Buah Kiwi dengan Metode Convolutional Neural Networks Menggunakan Keras,” Jurnal MEdia Informatika Budidarma, pp. 1309-1315, 2021.

[3] J. A. Pratama, "IMPLEMENTASI K-NEAREST NEIGHBOUR UNTUK KLASIFIKASI KUALITAS TEMBAKAU MENGGUNAKAN DIGITAL IMAGE PROCESSING BERBASIS ANDROID,” Universitas jember, Jember, 2015.

[4] D. T. Hermanto, S. Megira, D. Ninosari dan Kusrini, "IDENTIFIKASI TINGKAT KEMATANGAN BUAH STRAWBERRY MENGGUNAKAN GRAY LEVEL CO-OCCURANCE MATRIX (GLCM) DAN LAPLACIAN FILTER," dalam Seminar Nasional Teknologi Informasi dan Multimedia 2018, Yogyakarta, 2018.

[5] D. P. Pamungkas, "Ekstraksi Citra menggunakan Metode GLCM dan KNN untuk Indentifikasi Jenis Anggrek (Orchidaceae)," Innovation in Research of Informatics (INNOVATICS), pp. 51-56, 2019.

[6] F. M. D. Febrianan, R. R. Isnanto dan A. A. Zahra, "PENGENALAN GARIS UTAMA TELAPAK TANGAN DENGAN EKSTRAKSI CIRI MATRIKS KOOKURENSI ARAS KEABUAN MENGGUNAKAN JARAK EUCLIDEAN," Transient: Jurnal Ilmiah Teknik Elektro, p. 511, 2015.

[7] Ryansyah, "Identifikasi Tingkatan Warna Pada Kopi Roasting Menggunakan Metode HSV Berbasis Mobile," TIN: Terapan Informatika Nusantara, pp. 520-526, 2021.

[8] W. f. Roshandri, E. Utami dan A. B. Prasetio, "Segmentasi Luka Diabetes Menggunakan Masking Contour Image Processing,” Jurnal SISFOTRNIKA, pp. 111-123, 2021.

[9] F. Liantoni dan F. N. Annisa, "FUZZY K-NEAREST NEIGHBOR PADA KLASIFIKASI KEMATANGAN CABAI BERDASARKAN FITUR HSV CITRA,” JIPI (Jurnal Ilmiah Penelitian dan Pembelajaran Informatika), pp. 101-108, 2018.

[10] R. Hamidi, M. T. Furqon dan b. Rahayudi, "Implementasi Learning Vector Quantization (LVQ) untuk Klasifikasi Kulaitas Air Sungai,” Jurnal Pengembangan Teknologi Informasi dan Ilmu Komputer, pp. 1758-1763, 2017.

[11] U. Sudibyo, D. P. Kusumaningrum, E. H. Rachmawanto dan C. A. Sari, "OPTIMASI ALGORITMA LEARNING VECTOR QUANTIZATION (LVQ) DALAM PENGKLASIFIKASIAN CITRA DAGING SAPI DAN DAGING BABI BERBASIS GLCM DAN HSV," SIMETRIS, vol. 9, no. 1, pp. 1-10, April 2018.

[12] M. Sarimin, M. Bettiza , N. Hayaty dan S. Nugraha, "Implementasi HSV dan GLCM untuk Deteksi Kesegaran Ikan Bawal menggunakan Radial Basis Function Berbasis android," Jurnal Sustainable: Jurnal Hasil Penelitian dan Industri Terapan, pp. $1-7,2019$.

[13] F. M. Putra dan F. Syarifa, "Penerapan Learning Vector Quantization 3 (LVQ3) untuk Mengidentifikasi Citra Darah Acute Lymphoblastic Leukemia (ALL) dan Acute Myeloid Leukemia (AML)," CoreIT, pp. 27-33, 2018.

[14] M. A. Abilisa, R. Magdalena dan s. Sa'idah, "IDENTIFIKASI JENIS KULIT MANUSIA MENGGUNAKAN METODE GLCM DAN LVQ BERBASIS ANDROID,” dalam e-Proceeding of Engineering, bandung, 2021.

[15] D. Wandi, Fauziyah dan N. Hayati, "Deteksi Kelayuan Pada Bunga Mawar dengan Metode Transformasi Ruang Warna Hue Saturation Intensity (HSI) dan Hue Saturation Value (HSV)," JURNAL MEDIA INFORMATIKA BUDIDARMA, pp. 308 $316,2021$.

[16] C. Chotimah, A. Sofyan dan H. Tuti, "Respon Beberapa Pupuk Bokashi Padat Terhadap Hasil Produksi Tanaman Cabai Rawit Hiyung," AGROEKOTEK VIEW, pp. 7- 15, 2020.

[17] D. Putra, Pengolahan Citra Digital, Yogyakarta: Andi Offset, 2010. 